\title{
Corrigendum: KLHL3 mutations cause familial hyperkalemic hypertension by impairing ion transport in the distal nephron
}

Hélène Louis-Dit-Picard, Julien Barc, Daniel Trujillano, Stéphanie Miserey-Lenkei, Nabila Bouatia-Naji, Olena Pylypenko, Geneviève Beaurain, Amélie Bonnefond, Olivier Sand, Christophe Simian, Emmanuelle Vidal-Petiot, Christelle Soukaseum, Chantal Mandet, Françoise Broux, Olivier Chabre, Michel Delahousse, Vincent Esnault, Béatrice Fiquet, Pascal Houillier, Corinne Isnard Bagnis, Jens Koenig, Martin Konrad, Paul Landais, Chebel Mourani, Patrick Niaudet, Vincent Probst, Christel Thauvin, Robert J Unwin, Steven D Soroka, Georg Ehret, Stephan Ossowski, Mark Caulfield, International Consortium for Blood Pressure (ICBP), Patrick Bruneval, Xavier Estivill, Philippe Froguel, Juliette Hadchouel, Jean-Jacques Schott \& Xavier Jeunemaitre Nat. Genet. 44, 458-462 (2012); published online 11 March 2012; corrected after print 22 March 2012

In the version of this article initially published, two references were omitted, resulting in several statements being incorrectly attributed in the Online Methods. In the 'Ped01' subsection of the 'Whole-exome sequencing' section, two statements were attributed to ref. 21 . The correct reference for these statements has been added as ref. 27. In the 'Ped02' subsection of the 'Whole-exome sequencing' section, Annovar was incorrectly attributed to ref. 22. The correct reference has been added as ref. 28. As a result of the addition of these two references, former refs. 27-36 have been renumbered as refs. 29-38, respectively, in the text and reference list. In addition, author affiliation 7 was incorrectly given as Genes and Disease Program, Center for Genomic Regulation (CGR), Pompeu Fabra University, Barcelona, Spain. The correct affiliation is Genes and Disease Program, Center for Genomic Regulation (CGR) and Pompeu Fabra University, Barcelona, Spain. Similarly, affiliation 32 was incorrectly given as Genomic and Epigenetic Variation in Disease Group, Center for Genomic Regulation, Universitat Pompeu Fabra, Barcelona, Spain. The correct affiliation is Genomic and Epigenetic Variation in Disease Group, CGR and Pompeu Fabra University, Barcelona, Spain. These corrections have been made in the HTML and PDF versions of the article. 